\section{American Crystallographic Association Membership}

The American Crystallographic Association (ACA) was founded in 1949 through a merger of the American Society for X-Ray and Electron Diffraction (ASXRED) and the Crystallographic Society of America (CSA). The objective of ACA is to promote interactions among scientists who study the structure of matter at atomic (or near-atomic) resolution. These interactions will advance experimental and computational aspects of crystallography and diffraction. They will also promote the study of the arrangements of atoms and molecules in matter and the nature of the forces that both control and result from them.

Because of the expanding role that X-ray crystallography now plays in structural chemistry, protein engineering, drug design, materials science, the study of glasses, liquid crystals, minerals, and polymers, and the rapid development and utilization of synchrotron radiation, neutron, and electron diffraction facilities it seems appropriate to intitiate the first membership drive in nearly thirty years.

\section{The Benefits of ACA Membership}

Membership in the American Crystallographic Association is the best buy in the scientific world. The $\$ 25.00$ fee entitles a member to:

1. 12 issues of Physics Today each year.

2. The transactions of the ACA, the published proceedings of the annual ACA symposium on Frontier Topics.

3. Full abstracts of the annual meeting.

4. The ACA Newsletter, a timely bimonthly $24-50$ page newsletter with information on:

- Positions available (postdoctoral and permanent)

- Data base access and distribution (protein, organic, inorganic, metal, and powder diffraction data bases)

- Developments in diffraction and computer technology

- Listings of National and International meetings of interest to members

- Notes on the activities of the International Union of Crystallography

- Program and registration materials for the ACA meetings

5. Membership in one or more of the Special Interest Groups (SIG) that help define the content of the annual meetings. (Currently active SIGs include: Applied Crystallography, Small Angle Scattering, Biological Macromolecules, Small Molecules, and Neutron Diffraction).

6. Lower registration fees for the annual meeting.

For further information contact:

Mrs. Ethel E. Snider

Membership Secretary, ACA

American Institute of Physics

335 East 45 Street

New York, N.Y. 10017, U.S.A.

(see page 91 for membership application form)

\section{New - Mineral Powder Diffraction File}

The JCPDS-International Centre for Diffraction Data is continuing to improve the highly successful Mineral Powder Diffraction File. Now available is a new 2 volume set containing approximately 3,475 diffraction patterns covering 2,800 mineral species and also over 770 minerals newly described since 1980. All data have undergone a comprehensive computer review utilizing the NBS* EXAIDS83 system and have also been reedited with special reference to cell, space group, Z, calculated density, indices of refraction, mineral group, chemical formula, mineral nomenclature, polytype, symbols and indexing.

The Data Book contains copies of the Powder Diffraction File data card in Sets 1-35 of the Powder Diffraction File arranged in alphabetical order. Also included is both an index in PDF number sequence and a mineral group index. The all inclusive Search Manual contains a Hanawalt numerical section, a Fink numerical section, a chemical name section and an alphabetical section by mineral name. The new Mineral Powder Diffraction File in book form will prove to be a valuable asset, not only to libraries and laboratories engaged in mineralogy, but to all individuals and organizations involved in powder diffraction analysis.

Contact the International Centre for additional details. Place your order today to ensure early delivery. Price $\$ 550$.

Sales Department

JCPDS - International Centre for Diffraction Data

1601 Park Lane

Swarthmore, PA 19081, U.S.A.

(215) 328-9400

\section{The J. D. Hanawalt Powder Diffraction Award}

The award is sponsored by the JCPDS-International Centre for Diffraction Data. It is to be presented every three years for an important, recent contribution to the field of powder diffraction. The award will consist of a certificate and $\$ 1000$. The awardee is expected to submit an abstract and present a paper on the work being recognized at the IUCr Satellite Meeting on X-Ray Powder Diffractometry, Perth, Western Australia, August 20-22, 1987. Travel expenses to the meeting will be provided.

The award was first presented in 1983 to Dr. Ludo Frevel at the Denver X-ray Conference. Work that is eligible for consideration for the second presentation of the award must have been published between 1 January 1980 and 31 August 1985. There are no restrictions as to age, experience, or nationality of the recipient.

The 1986 selection committee members are Walter Eysel (Universitat Heidelberg), Ben Post (Polytechnic Institute, NY), Brian O'Connor (Western Australian Institute of Technology), Catharine Foris (DuPont) and Camden Hubbard (U.A. National Bureau of Standards). The selection committee will welcome suggestions, nominations, and documentation of accomplishments for possible recipients through 30 April 1986 from any interested persons. These 
can be sent to any committee member or directly to the chairman C. R. Hubbard, A257 MATL, National Bureau of Standards, Gaithersburg, Maryland 20899, U.S.A., (telex 894493).

\section{Grants-In-Aid from the JCPDS-Joint Committee on Powder Diffraction Standards}

Each year the JCPDS-International Centre for Diffraction Data extends financial support in the form of Grants-in-Aid to a limited number of scientists for the provision of X-ray powder data. These grants are intended to supplement existing funded projects involving the preparation and recording of data from new materials. First time grants are usually of the order of $\$ 2,000$ to $\$ 5,000$ for projects resulting in 10-25 new patterns. Proposals addressing the immediate needs of the powder diffraction community will be given highest priority, especially projects involving organic compounds and materials used in forensic investigations. Materials involved with any new and evolving technologies are also of specific interest.

Grants-in-Aid proposals will be considered from any qualified investigator who can demonstrate expertise in the preparation of high quality powder diffraction patterns, or in the synthesis of high purity materials, provided that such materials are of interest to the Grants-in-Aid Committee. All Grant-in-Aid recipients are required to prepare bi-

\section{Computer Comments}

Under this heading we hope to provide a means of communicating information concerning both new programs or systems and significant updates to existing ones. More specifically, if you have personal computer based programs for collecting, processing, and/or reporting diffraction data AND are willing to share them, we solicit your contributions. Guidelines for submissions to this column are identical to those required by the International Union of Crystallography, Journal of Applied Crystallography (1985) 18, 189, Guidelines for Computer Program Abstracts. Submission of a floppy diskette with a copy of the working program and a ASCII .DOCument file describing input data formats, restrictions, and cautions (while not presently required) is desirable. Commercial announcements are welcome.

Powder Diffraction provides this column as a service to its readers and, as such, cannot be held liable for the success or failure of the program described here. The editors reserve the right to determine the suitability of any contribution for inclusion. While this column is part of the Departments section, it is written and edited by Roy Garvey, North Dakota State University, Department of Chemistry, Fargo, ND 58105-5516, U.S.A., and Mark Holomany, JCPDS-Inter- annual reports on progress and extension of a Grant beyond a given year is contingent on satisfactory performance. Proposals should be submitted in accordance with specified guidelines and new proposals are reviewed in January of each year. A final decision is generally reached in March. All Grants become effective the beginning of the JCPDS fiscal year, currently 1st April.

Guidelines for the preparation of Grant proposals can be obtained from the JCPDS and proposals for grants should be addressed to:

Secretary, JCPDS-International Centre for Diffraction Data

1601 Park Lane

Swarthmore, PA 19081, U.S.A.

\section{Back issues of \\ Standard X-ray Diffraction Powder Patterns}

The National Bureau of Standards has on hand a limited supply of back issues of NBS Circular 539, Sections 1-10, as well as NBS Monograph 25, Sections 1-19. Individual copies may be obtained at no charge as long as supplies last.

Please contact: National Bureau of Standards

Building 223, Room A209

Washington D.C. 20899, U.S.A.

national Centre for Diffraction Data, 1601 Park Lane, Swarthmore, PA, 19081, U.S.A. Contributions should be directed to them.

\section{Tutorial Workshop: Personal Computing in X-Ray Diffraction}

Disk, DOS, Compute will be the theme for the Tutorial Workshop PERSONAL COMPUTING in X-RAY DIFFRACTION to be presented at the 35th Annual Denver Conference on Applications of X-ray Analysis at the University of Denver, University Park Campus, 4-8 August, 1986. Focussing on the powerful personal computers becoming available to the diffractionist, Roy Garvey (North Dakota State University, Fargo) will again coordinate a program reviewing a diversity of applications followed by a chance for hands on experience. A formal presentation directed to the "new comer" will be followed by a chance for hands on experience. The audience will separate into "interest groups" centered about demonstra- 